\section{Theory of Mind, Emotion Knowledge, and School Engagement in Emerging Adolescents}

\author{
Sandra Bosackia ${ }^{a,}{ }^{*}$, Flavia Moreirab ${ }^{b}$, Valentina Sitnik ${ }^{c}$, \\ Kathleen Andrews ${ }^{d}$, Victoria Talware
}

$\begin{array}{ll}\text { Received: } & 2 \text { April } 2019 \\ \text { Revised: } \quad 24 \text { May } 2019 \\ \text { Accepted: } \quad 20 \text { June } 2019 \\ \text { ISSN: 1307-9298 } \\ \text { Copyright @ IEJEE } \\ \text { www.iejee.com }\end{array}$

DOI: 10.26822/iejee.2019553349

\begin{abstract}
Theory of Mind (ToM), or the ability to attribute mental states to oneself and others to predict behavior is an important skill that helps adolescents to navigate through school. Building on emerging research on the cognitive and affective aspects of ToM and school engagement, this cross-sectional study explored ToM, emotion knowledge, and school engagement in 32 adolescents ( 22 females; Mage = 187.2 mos - 15.16 years, $S D=3.29$ ) from central Canada. Positive correlations were found between ToM and school engagement, controlling for language. Higher levels of experiences of guilt and shame were associated with higher levels of ToM and school engagment. Verbal ability significantly contributed to total perceptions of school engagement. Implications for adolescents' social cognition, mental health, and school experiences are discussed.
\end{abstract}

Keywords: Adolescents; Social Cognition; Empathy; School Engagement; Gender Differences

\section{Introduction}

Theory of Mind (ToM), or the ability to attribute mental states to oneself and others to predict behavior is an important social-emotional skill to develop during the transition to secondary school (Hughes, 2011; Lacey et al., 2017). Social-emotional skills such as perspective taking and empathy are especially important for the development of school engagement, memory and academic achievement, and prosocial relations (Ahmed et al., 2018; Estevez et al., 2018; Ross \& Tolan, 2017; Zorza et al., 2018). Although past studies have found positive associations among younger children's ToM, memory, and school success (Lecece et al., 2017; Lockl et al., 2017), and social relations (Feldman et al., 2014; Fink et al., 2015; Lecce et al., 2017), few studies explore relations among ToM, empathy, and school engagement in emerging adolescents. That is, to the best of our knowledge, there remains a lack of studies on the connections among ToM and related social-emotional skills, emotion knowledge, and school success in young adolescents (Campbell et al., 2018; Moore-McBride et al., 2016).

The present study takes a new approach and studies the connections between individual differences in ToM, emotion knowledge, and multiple dimensions of perceived school engagement in adolescence. First, it focuses on an understudied and often neglected developmental period in the ToM research area, namely, adolescence. Second, it adopts a multidimensional and psychoeducational focus to ToM and school engagement. Thirdly, given the lack of studies on the role of gender in social cognition and school engagement, we also examined gender-related differences (Devine \& Hughes, 2013; Bosacki, 2014).

Social Cognition, Emotion Knowledge, and Relationships during Adolescence

Adolescence is a unique developmental time as this period (approximately ages 12 to 18 ) represents a transition across many domains such as neurocognitive, emotional, social as well as physical with the hormonal influences of puberty (Blakemore, 2018). Early adolescents' increasingly sophisticated reflection and recursive thoughts about themselves and others play crucial roles in their personal and social lives (Van den Bos et al., 2016). However, following negative academic or social experiences, such as low grades, or conflict with teachers, parents, and peers, these sophisticated social-cognitive abilities may also have a negative impact on students' psychological well-being (Eccles \& Roeser, 2011). For example, the psychosocial theory of self-determination claims human well-being and healthy motivation (e.g., intrinsic motivation) are nourished by the fulfillment of three fundamental psychological needs: the need for competence, autonomy, and relatedness (Deci \& Ryan, 2014; Dweck, 1999; Pakarinen et al., 2018).

\section{ToM and School Engagement}

Researchers have just started to explore the influences of social understanding and social cognitive abilities on school achievement and vice versa (Greene et al., 2018; Wellman, 2016). Past studies with children and adolescents show that students who experience high levels of emotional competence are more likely to develop a positive attitude toward school, to successfully adjust to the world of school, and to improve grades and achievement (Denham, 2006; Tornare, et al., 2015). For example, Trentacosta and Izard et al. (2007) showed that emotion knowledge (the ability to interpret and name facial expressions) at age 5 predicted children's school achievements at age 9. More recently, Denham et al. (2012) found that 3- and 4-year-olds' emotion knowledge predicted teacher-reported school success a few months later.

Other studies have found that emotion understanding predicts young children's school adjustment (Mega et al., 2014), and correlates with performance on a standardized school competence measure (Garner \& Waajid, 2008). Regarding cognitive components of ToM such as perspective-taking and understanding false belief, Blair and Razza (2007) found preschoolers' false-belief performance predicted later letter

\footnotetext{
${ }^{* * *}$ Corresponding Author: Sandra Bosacki, Brock University, Niagara Region, 1812 Sir Isaac Brock Way, St. Catharines, ON L2S 3A1, Canada. E-mail: Sandra.bosacki@brocku.ca bFlavia Moreira, Brock University, Canada. E-mail: flavia.moreira@brocku.ca cValentina Sitnik, Brock University, Canada. E-mail: valentina.sitnik@brocku.ca đKathleen Andrews, McGill University, Canada. E-mail: katherine.andrews@mail.mcgill.ca e Victoria Talwar, ?McGill University, Canada. E-mail: victoria.talwar@mcgillu.ca
} 
knowledge. Given such results, even though belief and emotion understanding can be meaningfully differentiated (Cutting \& Dunn, 1999; Fink et al., 2015), they both potentially play a role in young people's school achievement. Such findings also support theoretical work and empirical evidence that suggest that belief and emotion understanding, while clearly distinguishable, are intricately connected indicators of a broader, overarching social understanding or ToM construct (Bialecka-Pikul et al., 2018; Devine \& Hughes, 2013; Hughes et al., 2011).

A crucial next step is to learn more about the developmental processes that connect social understanding with school achievement during adolescence. First, evidence is needed to elucidate the associations among adolescents' social cognitive abilities (perspective-taking, empathy), and school engagement during the secondary school years. For example, we need to determine whether more advanced levels of Theory of Mind or social understanding correlate with higher levels of school engagement. Furthermore, to help us understand these connections between social understanding and school outcomes, we need to investigate what kind of explanatory mechanisms that may account for the relations.

Adolescence also represents a unique period for psychosocial and self-development, with an intensified alertness to social comparisons as a mechanism for self-knowledge, particularly about emotions (Blakemore, 2018). However, it remains difficult to disentangle the specific influence of these social cognitive abilities such as ToM and empathy on the development of understanding emotions in adolescence (DeLury et al., 2018; Hughes \& Leekam, 2004). Moreover, little is known about how the different dimensions of ToM influence the development of emotion-knowledge such as self-conscious emotions including guilt and shame (Heerey et al., 2003; Spence \& Rapee, 2016). Given this lack of knowledge, especially within young adolescents, the goal of this study was therefore to examine the links among early adolescents' social cognitive abilities (ToM - affective and cognitive), emotion knowledge, and their perceived school engagement (cognitive or academic and psychological).

Research also suggests that the connection between social understanding and social competence may provide an important key to understanding children's school achievement (Lecece et al., 2014). A growing body of research shows that social competencies are strong predictors of school readiness and school success (Bakadorova \& Raufelder, 2019; Caprara et al., 2000). Children's and adolescents' peer relationships have been found to significantly contribute to school affect, school liking, and school performance (Campbell et al., 2018). Further, rejected children were more likely to show a decrease in academic achievement in the short and long term (Feldman et al., 2014).

\section{The Present Study}

The current study has two goals: First, we investigated the existence of relations between ToM and perceptions of school engagement. Second, building on the evidence above that suggests ToM and social competencies predict school achievement, and links between verbal ability, ToM (Flobbe et al., 2008), and school achievement (Leece et al., 2014), we also evaluated whether the above expected associations were independent of verbal ability. Finally, given the mixed past results on the role of gender in these variables (Brandone \& Klimek, 2018; Duckworth \& Seligman, 2006; Stensen et al., 2018), we also tested for gender differences.
To address these aims, we investigate socio-cognitive predictors of adolescents' school adjustment on one time point, adolescents between 15 and 16 years. In addition, we explored the cognitive and emotional aspects of ToM, as well as the psychological and cognitive domains of school engagement. Consistent with the previous work, we expected to find positive associations among individual differences in adolescents' ToM, empathic skills, and their perceptions of school engagement (in the third year of secondary school) over and above verbal ability.

\section{Method}

\section{Participants}

As part of a larger 5-year longitudinal study, this study describes the analyses of our Year 3 (2017-8) data obtained from Grade 10 students from 8 schools within Ontario, Canada $\left(N=32 ; 22\right.$ females; $M_{\text {age }}=187.2$ months -15.6 years, $S D=3.29$ )

\section{Measures}

Reading the mind in the eye test - third edition (RMET, Baron-Cohen et al., 2013)

Participants completed this measure as a paper-and-pencil task in a group session which assessed participants' ability to recognize complex mental states. The measure involved 36 items with each item containing a photograph of an expression with just the eyes showing. Four descriptive words, indicating different emotions, were listed and the participant was required to choose the word that best described the expression. Each item had one correct answer and was scored as one point. A higher score indicated a greater ability to read subtle emotions $(M=22.78, S D=$ 5.40).

\section{Strange stories (White, Happé, Hill, \& Frith, 2009)}

To assess participants' second order ToM or the ability to recognize and reason about complex mental states, we included a subset of five short stories about mental states were adapted from Happé's (1994) Strange Stories task (themes include a white lie, double bluff, lying, and persuasion). Each story depicted an everyday event in which the main protagonist said something that was not true. Participants were asked a justification question about why the participant made such a statement. Participants' responses were scored using the coding criteria developed by White et al., (2009) with 0 representing non-tangential or I don't know, 1 representing a response that incudes mention of action and is partly correct, and a score of 2 represents a correct response that mentions mental states or a psychological explanation with reference to persuasion, manipulating feelings, or trying to induce guilt/pity. Scores were summed and yielded a total Strange Story score that could range from 0 to $8(M=5.89, S D=2.28)$.

ToM second order false belief task (adapted from Astington, Pelletier, \& Homer, 2002)

This second order false belief task involves a short story that describes a scenario in which three characters are implicated in a social exchange that involves a false belief about a particular event (Astington et al., 2002). The participants are asked about the beliefs and emotions of the characters in the story, and tests the participants' understanding of evidence and truth $(M=3.47, S D=.67)$.

\section{Empathy (Interpersonal Reactivity Index (IRI, Davis, 1980)}

The IRI (Davis, 1980) is the most widely used psychometric test to evaluate both empathy and ToM. The test has 
been extensively investigated and validated (Artinger et al., 2014; Davis, 1980). The IRI is a self-report questionnaire that includes abstract descriptions of social interaction which participants respond to. It is a 28-item, 5-point Likert-scale test with four sub-scales: perspective-taking scale $(\mathrm{PT})$, fantasy scale (FS), empathic scale (EC), and personal distress scale (PD).

Test of self-conscious affect (TOSCA-3, Tangney et al., 2000; Tangney, Baumeister, \& Boone, 2004)

To assess one's understanding of self-conscious emotions such as shame, guilt, and blaming others, the Test of Self-Conscious Affect (TOSCA-3) was used. This 11 item self-report questionnaire consists of brief scenarios that measure shame, guilt, and blaming others proneness. The scenarios include subjects that are encountered in day-today life and to capture the possible reactions in such situations, each scenario is followed by 5 associated responses. The scores range from 1 (not likely) to 5 (most likely) with 3 subscales (shame self-talk, guilt self-talk, and blaming others). The lower the score indicates that you are seldom prone to this behaviour, while a higher score indicates that you often portray this behaviour, $(M=3.30, S D=.45)$. Convergent and divergent validity for the TOSCA scales has been well documented and the constructs of shame and guilt demonstrated a unique variance that is functionally distinct (Tangney, et al., 2004).

School engagement instrument (SEl, Appleton, Christenson, Kim, \& Reschly, 2006)

This 35-item Likert scale questionnaire assesses the engagement of students at school including cognitive and affective engagement (Appleton et al., 2006). It is comprised of 3 subscales for affective engagement (teacher-student relationships, peer support for learning, and family support for learning), and 3 subscales for cognitive engagement (control and relevance of school work, future goals and aspirations, and intrinsic motivation). There are also additional domains of behavioral engagement and disaffection. The responses range from "strongly disagree" to "strongly" agree" with a scoring range of 35-140. The SEI total mean is the sum of all items divided by 35 , psychological engagement $(M=3.10, S D=.49)$, and cognitive engagement $(M=3.39, S D=.34)$, total engagement $(M=3.02, S D=$ .35). Lower scores may be indicative of more absences, disciplinary incidents, or lower achievement performance (Appleton et al., 2006).

Table 1. Descriptive statistics, correlations and gender differences among study variables

\begin{tabular}{|c|c|c|c|c|c|c|c|c|c|}
\hline & 1 & 2 & 3 & 4 & 5 & 6 & 7 & 8 & 9 \\
\hline 1. WIAT Recepti Vocabulary & --- & & & & & & & & \\
\hline 2. IRI Total Score & -0.119 & --- & .404 & 0.18 & 0.29 & 0.31 & -0.107 & 0.175 & 0.214 \\
\hline 3. RME Total Score & $.417^{\star}$ & 0.315 & --- & 0.22 & 0.04 & 0.14 & 0.106 & -0.107 & 0.125 \\
\hline 4. Cognitive Engagement Score & $.502^{* *}$ & 0.094 & $.379^{*}$ & --- & 0.28 & $.696^{* *}$ & 0.219 & 0.118 & 0.114 \\
\hline 5. Psychological Engagement Score & $.402^{*}$ & 0.217 & 0.201 & $.420^{*}$ & --- & $.882^{* *}$ & 0.148 & 0.238 & -0.082 \\
\hline 6. Student Engagement Total Score & $.523^{* k}$ & 0.197 & 0.323 & $.776^{* *}$ & .899 & --- & 0.249 & 0.235 & -0.005 \\
\hline 7. Strange Stories Total Score (Spearmans) & 0.412 & -0.137 & -0.089 & 0.175 & 0.437 & 0.421 & --- & $.473^{*}$ & -0.087 \\
\hline 8. ToM 2nd Order Stories & 0.092 & -0.343 & -0.335 & 0.260 & 0.186 & 0.192 & 0.437 & --- & 0.109 \\
\hline 9. TOSC Total Score & 0.162 & 0.190 & 0.180 & 0.179 & -0.009 & 0.080 & 0.074 & 0.112 & $\cdots$ \\
\hline MEAN & 14.08 & 3.35 & 22.78 & 3.39 & 3.10 & 3.25 & 5.89 & 3.47 & 3.30 \\
\hline SD & 1.80 & 0.45 & 5.40 & 0.34 & 0.49 & 0.35 & 2.28 & 0.67 & 0.45 \\
\hline Diffrence Between Females and Males (T-Test) & & $2.72^{* *}$ & 0.64 & 0.01 & -0.23 & -0.15 & 0.08 & 0.79 & $3.02^{*+}$ \\
\hline MEAN F & & 3.49 & 23.18 & 3.39 & 3.12 & 3.25 & 5.92 & 3.55 & 3.46 \\
\hline MEAN M & & 3.04 & 21.78 & 3.39 & 3.16 & 3.28 & 5.83 & 3.33 & 2.96 \\
\hline
\end{tabular}

Wechsler individual achievement test - third edition (WIAT-III) This measure was used to assess participants' receptive language skills in Year 1 (2015-2016), $(M=14.08, S D=1.80)$ and was administered verbally by the researcher. The measure consisted of 19 items with each item having one correct answer. The participant was shown four pictures on one page and the researcher spoke one word, wherein the participant needed to say (or point to) the corresponding letter (A, B, C, or D) of the picture. Each item had a correct answer and was scored as following: DK for Don't Know $=0$, Correct $=1$, Incorrect $=0$. The maximum receptive vocabulary raw score was 19 and any raw score below 11 was not used. The higher score indicated a more advanced level of listening comprehension and receptive vocabulary skills.

\section{Results}

All presented categorical and inferential statitstics were performed using SPSS, version 25.0. Assumptions of normality were examined, as well as Skewness statistics for all study variables. Outliers' values were identified and removed to handle the skewness of the data. Except for Strange Stories variable, no violation of normality was detected.Within the framework of the main hypotheses, results below include descriptive statistics, t-tests (or MANCOVAs - controlling for age and language) for gender effects, and correlations among all main variables. Non-parametric tests were conducted to assess the Strange Stories variable.

\section{Descriptive and Gender Differences}

To investigate gender effects across the main variables, we conducted a between-subject MANCOVA using ToM, emotion understanding (IRI, TOSCA), and school engagement scores (SEI) as DVs and gender as IV, including the WIAT or verbal age (VA) and age as the covariates. Results showed that the effect of gender was significant for cognitive ToM (ToM 2nd order), $F(1,22)=10.87, p<.01$, and when controlling for age and verbal age, gender differences were also found in empathy or emotion understanding (IRI), $F(1,22)=4.75, p<.05$.

Table 1 shows the main results for the descriptive data, correlations and gender-differences for the main variables. Results from MANCOVA t-tests showed significant gender differences in emotion understanding (IRI, TOSC). Compared to boys, girls scored higher on empathy (IRI), $t(29)=2.72, p<.01$ (empathetic concern and personal dis-

Note: ${ }^{*}$ Correlation is significant at the 0.05 level (2-tailed). ${ }^{* *}$ Correlation is significant at the 0.01 level (2-tailed). 
tress), and self-conscious emotion understanding with a focus on shame $t(28)=2.56, p<.05$ and guilt $t(28)=3.54, p<$ .01 . No significant gender differences were found in the ToM measures - either affective (RMET) or cognitive (SS, 2nd ToM 2nd order), or in any of the school engagement measures (SEI).

Relations among ToM, Emotion Knowledge, and School Engagement

Table 1 shows the zero-order and partial correlations (controlling for language) among the main variables. Significant positive relations were found between ToM and perceptions of school engagement. That is, affective ToM (RMET) scores were positively correlated with the perceived cognitive engagement, and with the subscale of psychological engagement (teacher-student relationship) $(r=.396, p<.05)$. Similarly, cognitive ToM (SS, ToM 2 nd order) scores were also positively correlated with the subscale of psychological engagement (family support for learning) $\left(r_{s}=.547, p<.05\right)$. Controlling for language, affective ToM scores (RMET) were also significantly positively associated with empathy (IRI) $\left(r_{p}=.404, p<.05\right)$.

Regarding emotion knowledge and ToM, no relations were found between guilt/shame and ToM (cognitive or affective). However, significant positive associations were found for ToM (2nd order) and the empathy subscale (fantasy), $(r=.401, p<.05)$. Positive links were also found between subscale scores of self-conscious emotions (TOSC) and total empathy scores (IRI) including: empathy and shame, $r=.384, p<.05$; empathy and guilt $r=.427, p<.05$, and empathy and blaming others, $r=.471, p<.01$ ).

In addition, participants with relatively higher levels of empathy (IRI) and affective ToM (RMET) were more likely to report higher levels of self-conscious emotions (TOSC) such as shame, and to a greater extent, guilt. Significant positive links were also found between total school engagement (SEI) and self-conscious emotions (TOSC) (total school engagement and guilt, $r=.362, p<.05$ ). That is, those students who reported higher school engagement also reported higher levels of guilt.

To test for gender differences between correlations of the main variables, correlations were conducted on two separate samples divided according to gender (girls $=24$ boys $=10$ ). For girls only, positive associations were found between affective ToM (RMET) and total student engagement $(r=.493, p<.05)$, whereas for boys the correlation did not reach significance.

Finally, to test if ToM predicted school engagement, above and beyond the contribution of verbal ability, a hierarchical regression was run with total student engagement as the outcome variable, cognitive ToM (2nd order ToM, SS), and affective ToM (RMET) as predictor variables, and verbal ability (WIAT) as a control variable. Overall the mode was significant, $F(3,25)=3.23, p=.042$, and accounted for $21 \%$ of the variance in total student engagement. However, following verbal ability.

\section{Discussion}

The present study investigated the connections among Theory of Mind, emotion knowledge, and perceived school engagement in adolescence. Our first aim was to explore the connections among the main variables (controlling for language). Our second aim was to test for gender-differences. Guided by our research aims, results are discussed below within the context of past literature, followed by limitations and implications for education and future research.
Relations among ToM, emotion knowledge, and school engagement

The current study found positive relations among ToM, emotion knowledge, and school engagement. More specifically, we found positive links between affective and cognitive ToM and school engagement. Such findings support past research that shows children with higher ToM, also perform better in school academically (Durlak et al., 2011; Estevez et al., 2018; Mega et al., 2014; Tangney et al., 2004).

However, the present results also showed that those who scored higher on ToM and empathy may also experience greater feelings of guilt and shame (Leece et al., 2017; Lockl et al., 2017). Such findings support studies that suggest being skilled in understanding the perspectives and emotions of others may in part hinder one's private emotion knowledge in that it may reduce one's awareness and attention to the emotional self (Leary \& Guadagno, 2011). Cognitive ToM was also found to be positively linked to perceptions of positive family support for learning. More precisely, such positive links between cognitive ToM and students' perceptions of their relationships with their family show that these affective interactions also play a role in students' social and metacognitive abilities (Midgley et al., 1989). Thus, such findings support past research that suggests a bi-directional relation exists between social cognitive abilities and relationship quality in that family and teacher relations may reciprocally influence students' higher-level thinking about emotions and mental states (O'Connor \& McCartney, 2007; Pakarinen et al., 2018; Van den Bedem et al., 2018).

The current study's results also suggest that positive links exist among self-conscious emotions such as guilt and shame, ToM, and school engagement. The links between self-conscious emotions and ToM support the theories on emotions that suggest feelings such as guilt and shame are cognitively complex and include self-referential thought (Heerey et al., 2003), as well as an awareness of societal conventions and others' evaluations (Izard, 2007). In particular, a main distinctive feature of self-conscious emotions is that they involve self-evaluation, self-reflection, and self-representation. People are aware of, and reflect upon their actions and evaluate them against socio-cultural and moral norms and standards, and accordingly experience a variety of self-conscious emotions (Heerey et al., 2003; Tracy \& Robins, 2007).

This study also found positive links between school engagement and self-conscious emotions (especially guilt) which suggests that students who reported higher psychological engagement in school also reported higher levels of guilt. Such findings support work on the possible negative emotional implications of psychological engagement in learning as students who were psychologically engaged in school work were more likely to feel guilty (or vice versa).

(Tangney et al., 2004). Further, students who are more sensitive to psychological issues within the classroom, may tend to also be more sensitive to criticism and negative evaluations from teachers and/or peers (Leece et al., 2011; 2014).

Precocious self-conscious emotion understanding may also help to promote school engagement and ToM as such students may be more sensitive to others' emotions and be more receptive to learning from others. Such findings have important implications for education and suggest that teachers need to promote emotion sensitivity to others and oneself (Leece et al., 2014). That is, teachers 
need to serve as role models and refer to psychological or mental state language within the classroom and in their conversations with students (Venter \& Uys, 2019; Vera et al., 2018). In particular, within such conversations, teachers and those who work with youth should aim to avoid negative self-talk around shame and guilt which may lead to harmful psychosocial consequences to students' emotional well-being and their self-worth (Lazuras et al., 2018). Regarding students' perceptions of school engagement, results showed that adolescents' cognitive ToM (SS, ToM 2nd order) was positively related to their perceptions of their psychological engagement in school, especially peer and family support for learning. Such findings suggest that in addition to teachers and families, peers also play an important role in adolescents' learning and school experiences during secondary school. These findings also support past studies that show positive relations with peers may help to influence adolescents' experiences within the school and their overall emotional well-being (Leventen et al., 2018; Madjar et a., 2016; Pratt \& George, 2005). Therefore, the combined results of the influence of family and peers' relations on a students' school experiences and their self and social cognition support recent work that suggests high proficiency in ToM may have advantages and disadvantage for young adolescents' psychosocial development, school engagement, and mental well-being (Bosacki, 2016; Hughes, 2011; Leece et al., 2014).

\section{Gender Differences}

Our findings suggest that during middle adolescence (15 -16 years), girls and boys are more similar than they are different - especially in terms of perceived school engagement and social cognitive understanding. That is, girls and boys did not differ in terms of ToM or school engagement. In contrast, our results showed that gender may influence individual differences in emotion knowledge. More precisely, we found that girls were more likely than boys to be empathic in an emotional sense, and to engage in more self-talk about negative self-conscious emotions such as shame and guilt.

Such results provide support for past research on the further development of gender differences in the controllability and understanding of one's emotions increasing during school years and into adolescence (Brandone \& Klimek, 2018; Duckworth \& Seligman, 2006; Stensen et al., 2018). That is, past studies on children's social cognition shows that the students who hold incremental beliefs about emotions (as opposed to entity beliefs) are more likely to score high in self-regulation and well-being. Such findings suggest that gender may influence the links between students' emotion knowledge and relationships within school (Pakarinen et al., 2018; Spilt et al., 2012), mental well-being (Bosacki, 2016; Hughes, 2011; Lecce et al., 2014).

Although some past studies have found gender differences in ToM and school success (Brass et al., 2018; Devine \& Hughes, 2013), the present study's null findings regarding gender differences support other studies that show girls and boys may be more similar than different in terms of perceived school engagement (Campbell et al., 2018; Van der Aar et al., 2018). However, compared to boys, we found that girls showed positive relations between affective ToM and student engagement. Such a finding suggests that some girls may be emotionally sensitive to challenges experienced in the school context (e.g. peer or teacher-student conflict, academic challenges). Given that such challenges may lead to negative emotions such as worry, anxiety, and depression, and sensitivity to criticism (Lecce et al., 2011; 2014; Ramirez et al., 2018), future work should explore these variables in connection with self-knowledge and school engagement.
Studies show that educators could help advance adolescents' introspection skills and their ability to consciously monitor of one's own mental and emotional states by providing students with greater access to the challenges in controlling their emotions (Flavell, 2004). Adolescents' enhanced changeability beliefs may also reflect the kinds of emotion coaching and regulatory input they receive from others (Blakemore, 2018). In particular, given the present results and related research that show increasing gender differences in emotion understanding during adolescence (Stensen et al., 2018), males may need to receive more explicit instruction from teachers and parents regarding the need to calm down or stop feeling grumpy that moves beyond asking teens to 'snap out of it.' In contrast, females perhaps need more explicit talk from teachers regarding self-compassion (Gilbert \& Procter, 2006). That is, adolescents need parents and teachers to provide them with useful strategies to cope with such negative emotions such as relaxation and mindfulness activities (Eisenberg \& Morris, 2002; Rossiter et al., 2018).

For girls only, affective ToM was positively linked to student engagement. Given the lack of research on ToM and students' perceptions of school engagement, such findings support the need for further work. These key findings are discussed each in turn below within the context of previous research followed by limitations and implications for theory and practice.

Positive relations between cognitive ToM and parent-child relationships, and between affective ToM and teacher-student relationships, and perceived support for learning, are consistent with past studies that show ToM skills and emotion understanding may serve as social-cognitive tools to help children and adolescents to develop supportive relationships with others (Lecce et al., 2014; Pianta \& Stuhlman, 2004). Such skills may also help them to succeed in communicative and cooperative activities such as negotiation and persuasive skills (Curry \& Chesters, 2012; Gruneisen et al., 2015; Peterson et al., 2018).

From a more theoretical point of view, our results support the social-cultural, ecological perspective toward learning (Bronfenbrennet \& Morris, 2006). Such a theory claims that students' perspectives of academic school engagement are socially situated within the complex school context, and rely on interpersonal relationships (Bronfenbrenner \& Morris, 2006; Hamming \& Jozkowski, 2013; Morrow et al., 2014; Vygotsky, 1978). Past studies show that students learn in close collaboration with peers and family (Carpendale \& Lewis, 2004; Moll \& Tomasello, 2007). Thus, adolescents' academic engagement and success are likely to be strongly influenced by the quality of these social relationships (Pakarinen et al., 2018). For example, past studies report significant relations between emotion regulation and children's academic competence (measured via both teacher's ratings and children's scores on formal tests) in school-aged children (Trentacosta \& Izard, 2007). Such findings may be related to broader influences of executive function and self-regulatory skill. Such findings suggest that cognitive ability may represent only one piece of the larger school experience and may be experienced differently across genders.

Accordingly, a key direction for further research is to build on these findings, and to continue to explore how links between student's social cognitive and psychosocial development and school experiences change throughout the school system and across various gender orientations. In particular, researchers need to identify the interaction between social understanding, higher order cognitive functioning, and emotion regulation to predict adolescents' peer relationships, social behaviour, and subsequent 
school achievement including self-perceptions, academic school records, and teacher ratings (social, emotional, cognitive).

\section{Limitations and Implications}

Our study has a number of limitations that should be acknowledged, and which correspond with directions for further research. First, we used only one task to index language, (receptive vocabulary) and a more comprehensive measure including productive language would provide a more reliable measure. Second, a larger sample size would have provided more power to detect significant relations than in the present study. Third, additional factors such as executive function skills such as working memory and language may also have influenced the present results and future studies should include such variables (Ahmed et al., 2018; Lecce \& Bianco, 2018). Lastly, future studies should also explore the same study in different cultures as well as include adolescents from various social demographics.

Limitations notwithstanding, the present study holds important implications for education. As the results suggest, if ToM and related social-cognitive skills such as empathy and social recursive thinking helps adolescents to develop cooperative skills and relationships (Van den Bos et al., 2016), then researchers and educators may wish to focus on interventions in school to enhance adolescents' self-evaluation and ToM skills (Teding van Berkhout \& Malouff, 2016). Activities such as role-playing that asks students to take the perspective of others, and to imagine and discuss the emotional experiences of others in a play or story could encourage children to behave in a prosocial manner. In addition, students could read fiction and be encouraged to consider another character's perspective and imagine how the story would end.

Such use of inquiry and dialogue regarding emotions and epistemic cognition or the ways that they acquire, justify, and use knowledge might help them to develop a more open attitude to another's perspective and emotions in socio-cognitive conflicts (Brass et al., 2018; Greene et al., 2018). The present results may promote the development or inclusion of programs that encourage problem-solving, conflict resolution, perspective-taking reflective thinking and metacognitive abilities that may help young adolescents to solve social-cognitive conflict and promote prosocial behaviours in the classroom (Campbell et al., 2018; Yeager, 2017).

\section{Conclusions}

The results of the current study suggest that Theory of Mind and school engagement are positively related, controlling for language. Our findings also support the evaluation of separate domains (cognitive and affective) of Theory of Mind and school engagement, especially to identify problematic or protective social cognition and emotional well-being pathways for adolescents' school engagement. Our findings also suggest that gender may influence the relations among emerging adolescents' ToM, emotion knowledge, and school engagement. Theoretically, this study highlights the complex connections between adolescents' ToM, emotion knowledge, and school engagement. Practically, it provides empirical groundwork to support the need for teachers to foster ToM in secondary schools and for educational programs aimed to foster social cognitive and emotional skills and school engagement.

\section{Acknowledgements}

This research was supported in part by a grant from the Social Sciences and Humanities Research Council of Canada with grant no. 435-2015-0010 awarded to Bosacki and
Talwar. We also thank Malak Askar, Emily Eichner, Kendra Marotta, and Shanen Smith for their help with data collection and coding. We are grateful to the schools, children, and parents who participated in our research.

\section{References}

Ahmed, S. F., Tang, S., Waters, N. E., \& Davis-Kean, P. (2018, August 16). Executive function and academic achievement: Longitudinal relations from early childhood to adolescence. Journal of Educational Psychology. Advance online publication. http://dx. doi.org/10.1037/edu0000296

Appleton, J. J., Christenson, S. L., Kim, D., \& Reschly, A. L. (2006). Measuring cognitive and psychological engagement: Validation of the Student Engagement Instrument. Journal of School Psychology, 44, 427445. doi: 10.1016/j.jsp.2006.04.002

Astington, J. W., Pelletier, J., \& Homer, B. (2002). Theory of mind and epistemological development: the relation between children's second-order false-belief understanding and their ability to reason about evidence. New Ideas in Psychology, 20(2-3), 131-144. doi: 10.1016/S0732-118X(02)00005-3

Bakadorova, O., \& Raufelder, D. (2019): The relationship of school self-concept, goal orientations and achievement during adolescence, Self and Identity, doi: 10.1080/15298868.2019.1581082

Baron-Cohen, S., Wheelwright, S., Hill, J., Raste, Y., \& Plumb, I. (2001). RMET.

Białecka-Pikul, M., Szpak, M., Zubek, J., Bosacki, S., \& Kołodziejczyk, A. (2018). The psychological self and advanced theory of mind in adolescence. Self and Identity. Retrieved from https://doi.org/10.1080/15 298868.2018.1538900

Blair, C., \& Razza, R. P. (2007). Relating effortful control, executive function, and false belief understanding to emerging math and literacy ability in kindergarten. Child Development, 78, 647-663. Retrieved from http://dx.doi.org/10.1111/j.14678624.2007.01019.x.

Blakemore, S.-J. (2018). Inventing ourselves: The secret life of the teenage brain. New York: Doubleday.

Bosacki, S. (2016). Social cognition in middle childhood and adolescence: Integrating the personal, social, and educational lives of young people. Chichester, UK: Wiley.

Bosacki, S. (2014). A longitudinal study of children's theory of mind, self-concept, and gender-role orientation. International Electronic Journal of Elementary Education, 6, 213-228. Retrieved from https://iejee.com/ index.php/IEJEE/article/view/42

Brandone, A., \& Klimek, B. (2018): The developing theory of mental state control: Changes in beliefs about the controllability of emotional experience from elementary school through adulthood, Journal of Cognition and Development, doi: 10.1080/15248372.2018.1520711

Brass, N., McKellar, S., North, E., \& Ryan, A. (2018). Early adolescents' adjustment at school: A fresh look at grade and gender differences. Journal of Early Adolescence, doi: 10.1177/0272431618791291 
Bronfenbrenner, U., \& Morris, P. (2006). The bioecological model of human development. In: W. Damon (Series Ed.) \& R. M. Lerner (Vol. Ed.), Handbook of child psychology (Vol. 1). Theoretical models of human development (6th ed., pp. 793-828). New York: John Wiley.

Campbell, S., Zimmer-Gembeck, M., \& Duffy, A. (2018). Friends and education: Identity patterns across domains and associations with emotion dysregulation. Journal of Youth and Adolescence, https://doi. org/10.1007/s10964-018-0924-4

Caprara, G. V., Barbaranelli, C., Pastorelli, C., Bandura, A., \& Zimbardo, P. G. (2000). Prosocial foundations of children's academic achievement. Psychological Science, 11, 302-306. doi: 10.1111/1467-9280.00260

Carpendale, J., \& Lewis, C. (2004). Constructing an understanding of mind: the development of children's social understanding within social interaction. Behavioral and Brain Science, 27(1), 79-151. doi: 10.1017/S0140525X04000032

Curry, O., \& Chesters, M. (2012). 'Putting ourselves in the other fellow's shoes': The role of 'theory of mind' in solving coordination problems. Journal of Cognition and Culture, 12, 147-159. doi: 10.1163/156853712X633974

Cutting, A., \& Dunn, J. (2002). The cost of understanding other people: Social cognition predicts young children's sensitivity to criticism. Journal of Child Psychology and Psychiatry, 43, 849-860. http://dx.doi. org/10.1111/1469-7610.t01-1-00047.

Davis, M. (1980). A multidimensional approach to individual differences in empathy. JSAS Catalog of Selected Documents in Psychology, 10, 85.

Deci, E. L., \& Ryan, R. M. (2014). Autonomy and need satisfaction in close relationships: Relationships motivation theory. In N. Weinstein (Ed.), Human motivation and interpersonal relationships: Theory, research, and applications (pp. 53-73). New York, NY: Springer.

DeLury, D., Buffone, A., Ministero, L., \& Poulin, M. (2018): Compassion is partially selfless: Public self-concept accessibility following compassion and threat, Self and ldentity, DOI: 10.1080/15298868.2018.1554541

Denham, S. A., Bassett, H. H., Thayer, S. K., Mincic, M. S., Sirotkin, Y. S., \& Zinsser, K. (2012). Observing preschoolers' social-emotional behavior: Structure, foundations, and prediction of early school success. The Journal of Genetic Psychology, 173, 246278. http://dx.doi.org/10.1080/00221325.2011.59 7457.

Denham, S. (2006). Social-emotional competence as support for school readiness: What is it and how do we assess it? Early Education and Development, 17, 57-89. http://dx.doi.org/10.1207/ s15566935eed1701_4.

Devine, R., \& Hughes, C. (2013). Silent films and strange stories: Theory of mind, gender, and social experiences in middle childhood. Child Development, 84, 989-1003. https://doi.org/10.1111/cdev.12017

Dweck, C. (1999). Self-theories: Their role in motivation, personality, and development. Philadelphia, PA: Psychology Press.
Duckworth, A. L., \& Seligman, M. E. P. (2006). Self-discipline gives girls the edge: Gender in self-discipline, grades, and achievement test scores. Journal of $E d-$ ucational Psychology, 98, 198-208

Durlak, J. A., Weissberg, R. P., Dymnicki, A. B., Taylor, R. D., \& Schellinger, K. B. (2011). Enhancing students' social and emotional development promotes success in school: Results of a meta-analysis. Child Development, 82, 474-501. doi: 10.1111/j.14678624.2010.01564.x

Eccles, J. S., \& Roeser, R. W. (2011). Schools as developmental contexts during adolescence. Journal of Research on Adolescence, 21, 225-241. doi:10.1111/j.15327795.2010.00725.x

Estévez, E., Jiménez, T., \& Segura, L. (2018, September 27). Emotional intelligence and empathy in aggressors and victims of school violence. Journal of Educational Psychology. Advance online publication. http://dx.doi.org/10.1037/edu0000292

Feldman, M. A., Ojanen, T., Gesten, E. L., Smith-Schrandt, H., Brannick, M., Wienke, Totura, C. M., Alexander, L., Scanga, D., Brown, K. (2014). The effects of middle school bullying and victimization on adjustment through school: growth modeling of achievement, school attendance, and disciplinary trajectories. Psychology in the Schools, 51(10), 10461062. doi: 10.1002/pits.21799

Fink, E., Begeer, S., Peterson, C. C., Slaughter, V., \& de Rosnay, M. (2015). Friends, friendlessness, and the social consequences of gaining a theory of mind. British Journal of Developmental Psychology, 33, 1-17. Doi: $10.1111 /$ bjdp.12080

Flavell, J.H. (2004). Theory-of-Mind development: Retrospect and prospect. Merrill-Palmer Quarterly, 50(3), 274-290. doi: $10.1353 / \mathrm{mpq} .2004 .0018$

Flobbe, L., Verbrugge, R., Hendriks, P., \& Kr€amer, I. (2008). Children's application of theory of mind in reasoning and language. Journal of Logic, Language and Information, 17, 417-442. doi:10.1007/s10849-0089064-7

Garner, P. W., \& Waajid, B. (2008). The associations of emotion knowledge and teacher-child relationships to preschool children's school related developmental competence. Journal of Applied Developmental Psychology, 29, 89-100. http://dx.doi.org/10.1016/j.appdev.2007.12.001.

Gilbert, P., \& Procter, S. (2006). Compassionate mind training for people with high shame and self-criticism: Overview and pilot study of a group therapy approach. Clinical Psychology \& Psychotherapy, 13(6), 353-379. doi: 10.1002/cpp.507

Greene, J., Cartiff, B., \&, Duke, R. (2018). A meta-analytic review of the relationship between epistemic cognition and academic achievement. Journal of Educational Psychology, 110, 1084-1111.

Griffin Jr., A. A., Caldarella, P., Sabey, C. V., \& Heath, M. A. (2017). The effects of a buddy bench on elementary students' solitary behavior during recess. International Electronic Journal of Elementary Education 10(1), 27-36. doi: 10.26822/iejee.2017131884 
Grüneisen, S., Wyman, E., \& Tomasello, M. (2015). “I know you don't know I know..." Children use second-order false-belief reasoning for peer coordination. Child Development, 86(1), 287-293. doi: 10.1111/ cdev.12264

Hamming, B., \& Jozkowski, K. (2013). Academic achievement, violent victimization, and bullying among U.S. high school students. Journal of Interpersonal Violence, 28(7),1424-1436.

Happé, F. G. E. (1994). An advanced test of theory of mind: Understanding of story characters' thoughts and feelings by able autistic, mentally handicapped, and normal children and adults. Journal of Autism and Developmental Disorders, 24, 129-154. http:// dx.doi.org/10.1007/BF02172093

Heerey, E., Keltner, D., \& Capps, L. (2003). Making sense of self-conscious emotion: Linking theory of mind and emotion in children with autism. Emotion, 3, 394-400. doi: 10.1037/1528-3542.3.4.394

Hughes, C. (2011). Social understanding and social lives: From toddlerhood through to the transition to school. Hove, UK: Psychology Press.

Hughes, C. (2016). Theory of mind grows up: Reflections on new research on theory of mind in middle childhood and adolescence. Journal of Experimental Child Psychology, 149, 1-5. http://dx.doi. org/10.1016/j.jecp.2016.01.017.

Hughes, C., \& Ensor, R. (2011). Individual differences in growth in executive function across the transition to school predict externalizing and internalizing behaviors and self-perceived academic success at age 6. Journal of Experimental Child Psychology. http://dx.doi.org/10.1016/j.jecp.2010.06.005.

Hughes, C., \& Leekam, S. R. (2004). What are the links between theory of mind and social relations? Review, reflections and new directions for studies of typical and atypical development. Social Development, 13, 590-619. Retrieved from http://dx.doi. org/10.1111/j.1467-9507.2004.00285.x.

Izard, C. E. (2007). Basic emotions, natural kinds, emotion schemas, and a new paradigm. Perspectives on Psychological Science, 2(3), 260-280. doi: 10.1111/j.1745-6916.2007.00044.x

Lacey, A., Cornell, D., \& Konold, T. (2017). The relations between teasing and bullying and middle school standardized exam performance. Journal of Early Adolescence, 37(2), 192-221. doi: $10.1177 / 0272431615596428$

Lazuras, L., Ypsilanti, A., Powell, P., \& Overton, P. (2018). The roles of impulsivity, self-regulation, and emotion regulation in the experience of self-disgust. Motivation and Emotion, doi.org/10.1007/s11031018-9722-2

Leary, M. R., \& Guadagno, J. (2011). The role of hypo-egoic self-processes in optimal functioning and subjective well-being. In K. M. Sheldon, T. Kashdan, \& M. F. Steger (Eds.), Designing positive psychology: Taking stock and moving forward (pp. 135-146). New York, NY: Oxford University Press.

Lecce, S., \& Bianco, F. (2018). Working memory predicts changes in children's theory of mind during middle childhood: A training study. Cognitive Development, 47, 71-81. doi: 10.1016/j.cogdev.2018.04.002
Lecce, S., Bianco, F., Devine, R. T., Hughes, C., \& Banerjee, R. (2014). Promoting theory of mind in middle childhood: A training program. Journal of Experimental Child Psychology, 126, 52-67. http://dx.doi. org/10.1016/j.jecp.2014.03.002.

Lecce, S., Caputi, M., Hughes, C. (2011). Does sensitivity to criticism mediate the relationship between theory of mind and academic achievement? Journal of Experimental Child Psychology, 110, 313-331. doi: 10.1016/j.jecp.2011.04.011

Lecce, S., Caputi, M., \& Pagnin, A. (2014). Long-term effect of theory of mind on school achievement: The role of sensitivity to criticism. European Journal of Developmental Psychology, 11, 305-318. doi: 10.1080/17405629.2013.821944

Lecce, S., Caputi, M., Pagnin, A., Banerjee, R. (2017). Theory of mind and school achievement: The mediating role of social competence. Cognitive Development, 44, 85-97. doi: 10.1016/j.cogdev.2017.08.010

Leventen, J., Merrill, N., \& Bauer, P. (2018). Neural response to emotion related to narrative socialization of emotion in school-age girls. Journal of Experimental Child Psychology, https://doi.org/10.1016

Lockl, K., Ebert, S., \& Weinert, S. (2017). Predicting school achievement from early theory of mind: Differential effects on achievement tests and teacher ratings. Learning and Individual Differences, 53, 93-102. doi: 10.1016/j.lindif.2016.11.007

Madjar, N., \& Cohen-Malayev, M. (2016). Perceived school climate across the transition from elementary to middle school. School Psychology Quarterly, 31, 270288. doi: $10.1037 /$ spq0000129

Mega, C., Ronconi, L., \& De Beni, R. (2014). What makes a good student? How emotions, self regulated learning, and motivation contribute to academic achievement. Journal of Educational Psychology, 106(1), 121-131. doi:10.1037/a0033546

Midgley, C., Feldlaufer, H., \& Eccles, J. S. (1989). Student/ teacher relations and attitudes toward mathematics before and after the transition to junior high school. Child Development, 60(4), 981-992. doi:10.2307/1131038

Moll, H., \& Tomasello, M. (2007). Cooperation and human cognition: The Vygotskian intelligence hypothesis. Philosophical Transactions of the Royal Society B, 01 10. doi:10.1098/rstb.2006.2000

Moore-McBride, A., Chung, S., \& Robertson, A. (2016). Preventing academic disengagement through a middle-school-based social and emotional learning program. Journal of Experimental Education, 39, 370-385. doi: 10.1177/1053825916668901

Morrow, M. T., Hubbard, J. A., \& Swift, L. E. (2014). Relations among multiple types of peer victimization, reactivity to peer victimization, and academic achievement in fifth-grade boys and girls. Merril-Palmer Quarterly, 60(3), 302-327.

O'Connor, E. E., \& McCartney, K. (2007). Examining teacher-child relationships and achievement as part of an ecological model of development. American Educational Research Journal, 44, 340-369. 
O'Connor, M., Cloney, D., Kvalsvig, A., \& Goldfeld, S. (2019). Positive mental health and academic achievement in elementary schools: New evidence from a matching analysis. Educational Researcher, 48(4), 205-216. doi: 10.3102/0013189X19848724

Pakarinen, E., Silinskas, G., Hamre, B., \& Metasapelto, R.-L., Lerkkanen, M.-K., \& Nuri, J-E. (2018). Crosslagged associations between problem behaviors and teacher-student relationships in early adolescence. Journal of Early Adolescence, doi: $10.1177 / 0272431617714328$

Peterson, C.C., Slaughter, V., \& Wellman, H.M. (2018). Nimble negotiators: How theory of mind (ToM) interconnects with persuasion skills in children with and without ToM delay. Developmental Psychology, 54(3), 494-509. doi: 10.1037/dev0000451

Pianta, R. C., \& Stuhlman, M. W. (2004). Teacher-child relationships and children's success in the first years of school. School Psychology Review, 33, 444-458.

Pishghadam, R., \& Abbasnejad, H. (2016). Emotioncy: A potential measure of reliability. International Electronic Journal of Elementary Education, 9(1), 109-123.

Pratt, S., \& George, R. (2005). Transferring friendships: Girls' and boys' friendships in the transition from primary to secondary school. Children \& Society, 19, 16- 26. doi:10.1002/chi.830

Ramirez, G., Fries, L., Gunderson, E., Schaeffer, M., Maloney, E., Beilock, S., \& Levine, S. (2018). Reading anxiety: An early affective impediment to children's success in reading, Journal of Cognition and Development, doi: 10.1080/15248372.2018.1526175

Roeser, R., \& Pinela, C. (2014). Mindfulness and compassion training in adolescence: A developmental contemplative science perspective. New Directions for Youth Development, 142, 9-30. doi: 10.1002/ yd.20094

Ross, K., \& Tolan, P. (2017). Social and emotional learning in adolescence: Testing the CASEL model in a normative sample. Journal of Early Adolescence. doi:10.1177/0272431617725198

Rossiter, R., Clarke, D., \& Shields, L. (2018). Supporting young people's emotional wellbeing during the transition to secondary school in regional Australia. Australian \& International Journal of Rural Education, 28(1), 73-85.

Spence, S., \& Rapee, R. (2016). The etiology of social anxiety disorder: An evidence-based model. Behavior Research and Therapy, 86, 50-67. doi:10.1016/j. brat.2016.06.007

Spilt, J. L., Koomen, H. M. Y., Thijs, J. T., \& van der Leij, A. (2012). Supporting teachers' relationships with disruptive children: The potential of relationship-focused reflection. Attachment \& Human Development, 14, 305-318. doi:10.1080/14616734.2012.67 2286

Stensen, A., Leventon, J., \& Bauer, P. (2018). Emotion effects on memory from childhood through adulthood: Consistent enhancement and adult gender differences. Journal of Experimental Child Psychology, Retrieved from https://doi.org/10.1016/j. jecp.2018.09.016
Tangney, J. P., Dearing, R. L., Wagner, P. E., \& Gramzow, R. (2000). The Test of Self-Conscious Affect-3 (TOSCA-3). Fairfax, VA: George Mason University.

Tangney, J., Baumeister, R., \& Boone, A. (2004). High self-control predicts good adjustment, less pathology, better grades, and interpersonal success. Journal of Personality, 72(2), 271-324.

Teding van Berkhout, E., \& Malouff, J. M. (2016). The efficacy of empathy training: A meta-analysis of randomized controlled trials. Journal of Counseling Psychology, 63, 32-41. doi: 10.1037/cou0000093

Tornare, E., Czajkowski, N. O., \& Pons, F. (2015). Children's emotions in math problem solving situations: Contributions of self-concept, metacognitive experiences, and performance. Learning and Instruction, 39, 88-96. doi: 10.1016/j.learninstruc.2015.05.011

Tracy, J. L., \& Robins, R. W. (2004). Putting the self into self-conscious emotions: A theoretical model. Psychological Inquiry, 15(2), 103-125. doi: 10.1207/ s15327965pli1502_01

Trentacosta, C. J., \& Izard, C. E. (2007). Kindergarten children's emotion competence as a predictor of their academic competence in first grade. Emotion, 7, 77-88. http://dx.doi.org/10.1037/15283542.7.1.77.

Van den Bos, E., de Rooij, M., Sumter, S., \& Westenberg, P. (2016). Continued development of recursive thinking in adolescence: Longitudinal analyses with a revised thinking test. Cognitive Development, 37, 2841. doi: 10.1016/j.cogdev.2015.11.002

Van den Bedem, Willems, D., Dockrell, J., van Alphen, P., \& Rieffe, C. (2018). Interrelation between empathy and friendship development during (Pre)Adolescence and the moderating effect of developmental language disorder: A longitudinal study. Social Development. doi: $10.1111 /$ sode. 12350

Van der Aar, L, Peters, S., \& Crone, E. (2018). The development of self-views across adolescence: Investigating self-descriptions with and without social comparison using a novel experimental paradigm. Cognitive Development, 48, 256-270. doi: 10.1016/j. cogdev.2018.10.001

Venter, E., \& Uys, H. (2019). Group therapy for early adolescent relationship problems between girls. International Journal of Adolescence and Youth. https://doi. org/10.1080/02673843.2018.1509794

Vera, E., Hill, L., Daskalova, P., Chandler, N., Boots, T., Galvin, S., \& Polanin., M. (2018). Promoting upstanding behavior in youth: A proposed model. Journal of Early Adolescence. doi: 10.1177/0272431618798514

Vygotsky, L. S. (1978). Mind in society. Cambridge, MA: Harvard University Press.

Wellman, H. (2016). Social cognition and education: theory of mind. Pensamiento educativo. Revista de Investigación Educacional Latinoamericana, 53, 1-23. http://dx.doi.org/10.7764/pel.53.1.2016.14.

Wechsler, D. (2010). WIAT-III.

White, S., Happé, F., Hill, E., \& Frith, U. (2009). Revisiting the strange stories: Revealing mentalizing impairments in autism. Child Development, 80(4). 1097 1117. doi: 0009-3920/2009/8004-0012 
Yeager, D. S. (2017). Social and emotional learning programs for adolescents. Future of Children, 27, 7394.

Zorza, J. P., Marino, J., de Lemus, S., \& Acosta Mesas, A. (2013). Academic performance and social competence of adolescents: Predictions based on effortful control and empathy. The Spanish Journal of Psychology, 16, e87, 1-112. doi:10.1017/sjp.2013.87

Zhang, T., Wang, Z, Liu, G., \& Shao, J. (2019). Teachers' caring behavior and problem behaviors in adolescents: The mediating roles of cognitive reappraisal and expressive suppression. Personality and Individual Differences, https://doi.org/10.1016/j. paid.2018.10.005 